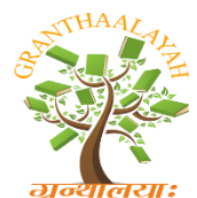

Social

\section{MODELING QUALITY EDUCATION IN A STATE UNIVERSITY}

\author{
Abel Alejandro U. Flores, Jr. * \\ ${ }^{* 1}$ University Research and Development Services, University of Eastern Philippines, University \\ Town, Northern Samar, Philippines 6400
}

Keywords: Quality Education; Modeling; State University; Quality Assurance; Total Quality Management.

Cite This Article: Abel Alejandro U. Flores, Jr. (2019). "MODELING QUALITY EDUCATION IN A STATE UNIVERSITY." International Journal of Research - Granthaalayah, 7(1), 184-189. https://doi.org/10.29121/granthaalayah.v7.i1.2019.1047. 


\section{Introduction}

The swiftness and scope of the phenomenon of globalization has caught the world by surprise, forcing organizations the world over to become more "quality-oriented", aspiring to be certified compliant to international standards in product design, manufacturing processes, testing, inspection, and services. Globalization's impact on education, especially in developing countries, becomes more pronounced, widening the knowledge gap due to the technological divide. Thus, a dualistic system of higher education emerges where select universities participate in global education, while technologically handicapped schools remain isolated and stagnant (Tullao, 2003).

The University of Eastern Philippines, the first State University in the Visayas, is a public, nonsectarian, and non-profit institution of higher learning that provides technical and professional training, advanced instruction in literature, philosophy, the sciences, and the arts. Likewise, it provides for the promotion of scientific and technological researches and contributes to the growth and dissemination of knowledge, enjoy academic freedom, and institutional autonomy (University Code, 2007).

In its desire to be at par with world standards, the University has embarked on an external accreditation of its programs to inform the market of its compliance with rigorous standards set by the government through the Commission on Higher Education (CHED).

\section{Methodology}

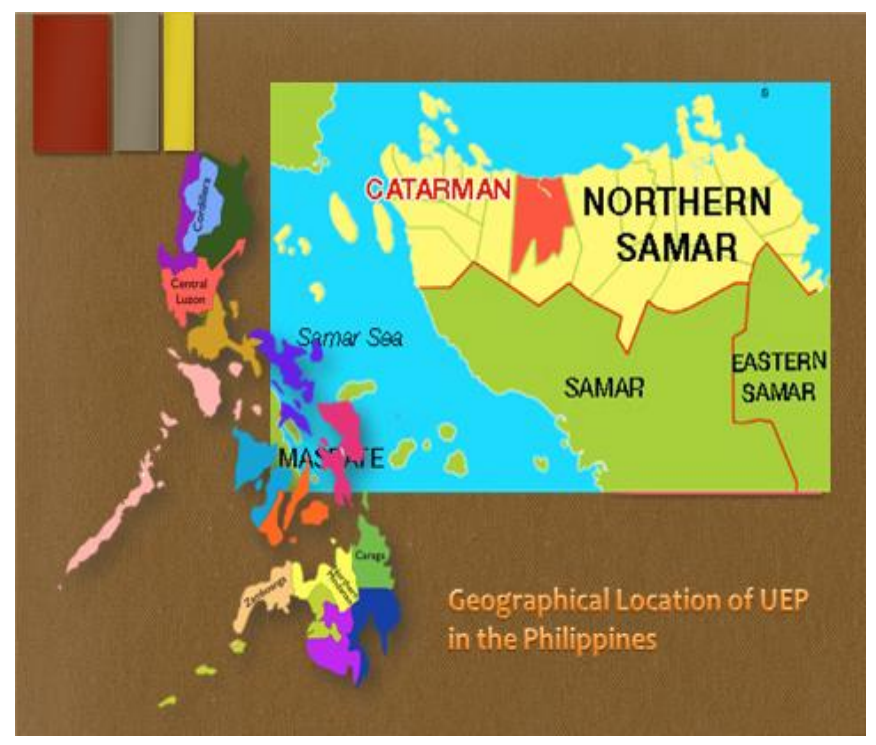

Qualitative data were taken from the responses of key informants and other groups of respondents to open-ended questions in a researcher-made questionnaire. Conceptual themes and/or specific ideas on quality higher education were elicited from key informants through interviews, which included the Vice Presidents, College Deans, and three arbitrarily chosen Administrative Unit Heads. Other respondents were randomly selected from the students, faculty members, the community, and alumni. 


\section{Results and Discussion}

From analysis of quantitative results of stakeholders' views on quality education, it is clear they generally agree the institution must clearly focus on its vision and mission while determined to carry out its mandates as stipulated in the strategic plan.

Total Quality Management (TQM) was the main theory with which this investigation has been anchored on. In the quest for world-class quality, the institution has defined and established systems and procedures, policies and guidelines, in the attainment of clientele satisfaction, involving continuous improvement of processes resulting in high quality educational services. Its key components are herein discussed.

Accreditation, whether institutional or program, has been identified as key to achieving quality in education. It is viewed as a quality management mechanism in adjunction to the minimum quality requirements stipulated for institutions and programs, and verified by CHED. Its success can be gauged in terms of performance indicators such as employment, income levels of new graduates, and percentage of passes in professional board examinations. This highlights the importance of accreditation in the enhancement of quality in higher education in the Philippines (Arcelo, 2003).

Numerous surveys found out that employees' hearty appetite for feedback too often goes unfulfilled such that $43 \%$ of employees feel that they do not get enough guidance to improve their performance. In this context, the University has established a Management Information System for the purpose of providing timely and accurate feedback on its programs' relevance, operational efficiency, and dealings with its stakeholders, a manifestation of the management's recognition of the importance of an effective and efficient feedback mechanism.

Sir William Slim once quoted: "Leadership is of the spirit, compounded of personality and vision; its practice is an art" (Moseley, Pietri, and Moseley, 2008). Admittedly, there is disagreement about definitions of leadership, stemming from the fact that it involves a complex interaction among the leader, the followers, and the situation. One leadership expert concluded: "Leaders manage and managers lead, but the two activities are not synonymous"; although leadership and management overlaps, each entails a unique set of activities or functions. All told, organizational success requires a combination of effective leadership and management hence today's leaders need to be effective at both leading and managing (Kreitner and Kinicki, 2008).

Synergy means that the whole is greater than the sum of its parts, a concept especially applicable in the use of teams and ad hoc task forces in problem solving. To achieve synergy and to gain the most from the employees, it is important for supervisors to understand the basic concepts of team development because work groups produce the synergistic effect needed for the organization to achieve its goals.

Experience has demonstrated that empowered, decisive, competent, and mutually accountable teams are often the most successful. Today's workplace is indeed undergoing immense and permanent changes, with organizations being "reengineered" for greater speed, efficiency, and flexibility. 
In education, the need for rethinking and redesigning processes to dramatically improve costs, quality, service, and speed has been uncovered. In the University of Eastern Philippines, particularly, the periodic redesign of the curriculum content (considered by AACCUP [2005] as occupying the center stage in any educational program) is very necessary to keep it abreast with the trends in the profession and maintain, or even enhance, the quality of higher education.

Kreitner and Kinicki (2008) defines organizational culture as "the set of shared, taken-for-granted implicit assumptions that a group holds and that determines how it perceives, thinks about, and reacts to its various environments." Organizational culture is not determined by fate, but formed and shaped by the combination and integration of everyone working in the organization. Similarly, organizational commitment reflects the extent to which individuals identify with organizations. It is thus a force that binds an individual to a course of action of relevance to one or more targets (Kreitner and Kinicki, 2008).

Espoused values represent aspirations, values, and norms generally established by the organization's founder and the top management team. It is explicitly communicated to employees, managers, and clientele, with the hope of directly influencing their behavior. The University of Eastern Philippines espouses its core values as relevance, integrity, productivity, and excellence aspirations it hopes to instill, nurture, and develop among its employees and students.

In any organization, financial resources such as money, capital and credit are very necessary to fund its operations and activities geared towards the achievement, attainment, or fulfillment of its vision and mission. The sound financial foundation of accredited institutions allows for the financing of quality-enhancing activities for the institution to continuously strengthen excellence (AACCUP, 2005). Objectives are also crucial to effective planning, and only if one first knows where he is heading can he effectively plan to get there hence, objectives should clearly be stated and the expected outcomes of instruction, such as skills, knowledge, and other competencies, values, and attributes of graduates be enunciated vividly. AACCUP (2005) has also qualified that the quality and adequacy of an institution's physical plant and facilities determine to a large measure the successful implementation of its curricular programs. Generally, the site should be in a wholesome environment conducive to learning, safe from traffic hazards and pollution, with a well-planned campus and functionally designed buildings equipped with sufficient furniture and fixtures. All these should complement institutional and program effectiveness.

\section{Conclusion}

The United Nations Educational, Scientific, and Cultural Organization (UNESCO), the only body in the United Nations with a mandate for education, adds that quality assurance can only be effective when all stakeholders understand and embrace its challenges and benefits. Developing a culture of quality requires a committed stewardship from higher education leaders (Ruiz and Sabio, 2012). The interplay of these important components - key ingredients - for a sustainable quality of education that must be incorporated and made part and parcel of a total quality management apparatus in a State higher education institution. 


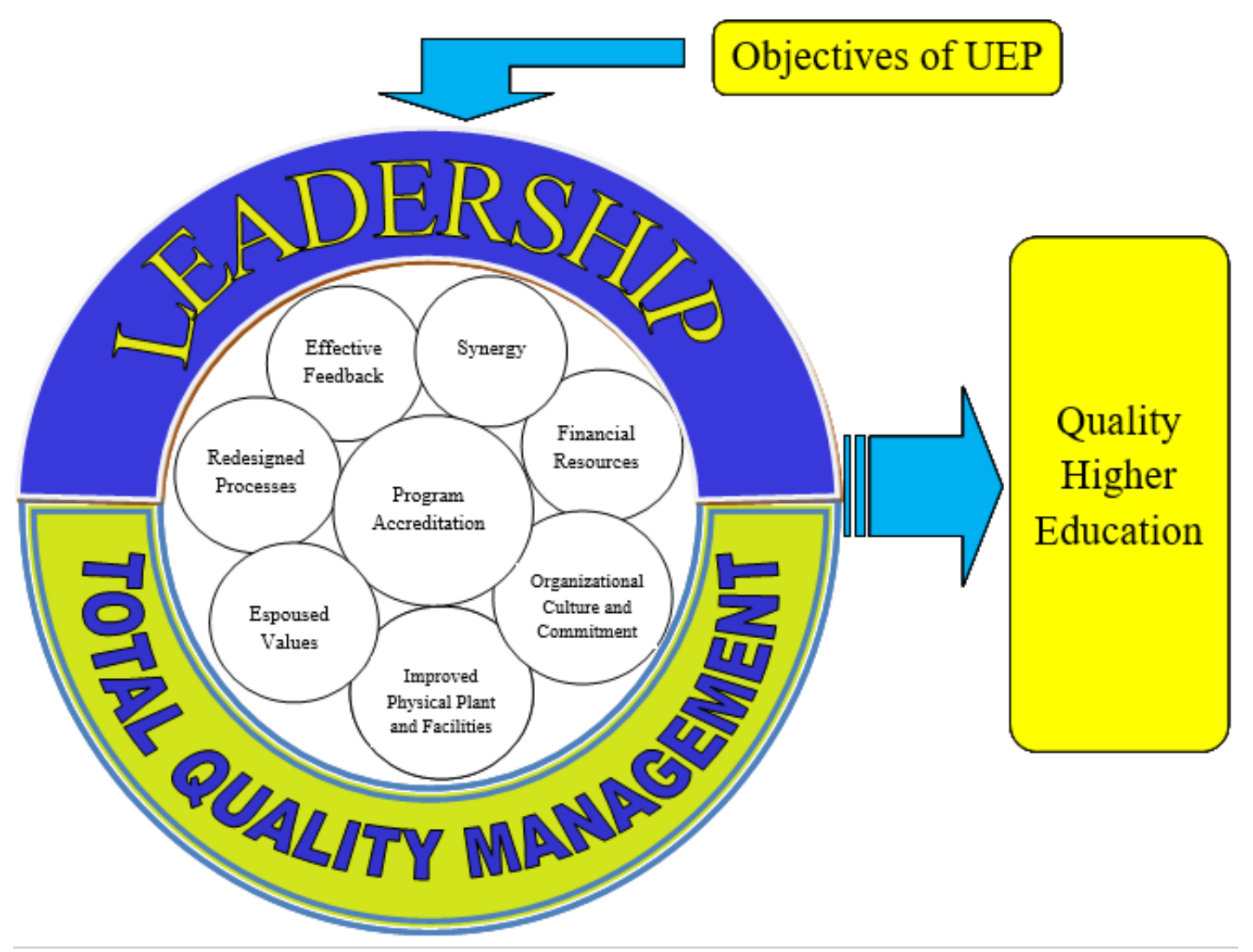

Figure 2: Model for Quality Education in the University of Eastern Philippines

\section{Recommendation}

To ensure sustainability of educational program quality in the University, there is a need to strengthen the institution's instructional mandate by realigning qualified and competent faculty members to academic units whose course programs entail government licensure examinations. Program accreditation must also be pursued and sustained, making the University relevant and matched with trends in the changing times, as well as strengthening its corporate structure and strategy to generate more funds for investment in more modern facilities, equipment, and upgrading of human resources in the pursuit of its vison and mission.

\section{References}

[1] AACCUP. (2005). Master survey instrument for the accreditation of programs. The Accrediting Agency of Chartered Colleges and Universities in the Philippines. Lobster Printing, Pasay City, Philippines. (ISBN 971-93221-0-1)

[2] Arcelo, A. A. (2003). In pursuit of continuing quality in higher education through accreditation: The Philippine experience. International Institute for Educational Planning. United Nations Educational, Scientific, and Cultural Organization (UNESCO). 7 - 9 rue Eugene Delacroix, 75116 Paris, France.

[3] Kreitner, R. and Kinicki, A. (2008). Organizational behavior. 5th Ed. McGraw Hill Companies, Inc., New York, USA. 
[4] Moseley, D. C., Pietri, P. H., and Moseley, D. C. Jr. (2008). Supervisory management: The art of inspiring, empowering, and developing people. 7th Ed. Thomson Higher Education, Mason, Ohio, USA.

[5] Ruiz, A. J. and Junio-Sabio, C. (2012). Quality assurance in higher education in the Philippines. Asian Journal of Distance Education. The Asian Society of Open and Distance Education (http://www.AsianJDE.org).

[6] Tullao, T. Jr., S. (2003). Higher education and globalization: An integrative report. In: Education and Globalization. Philippine APEC Study Center Network (PASCN) and Philippine Institute for Development Studies (PIDS). Makati City, Philippines.

[7] University of Eastern Philippines (UEP). (2007). Revised university code. University of Eastern Philippines, University Town, Northern Samar.

*Corresponding author.

E-mail address: abelalejandrofloresjr@ gmail.com 